\title{
Light and sporadic physical activity overlooked by current guidelines makes older women more active than older men
}

\author{
Shiho Amagasa ${ }^{1}$, Noritoshi Fukushima ${ }^{1}$, Hiroyuki Kikuchi ${ }^{1}$, Tomoko Takamiya ${ }^{1}$, Koichiro Oka $^{2}$ and Shigeru Inoue ${ }^{1 *}$
}

\begin{abstract}
Background: Men are generally believed to be more physically active than women when evaluated using current physical activity (PA) guidelines, which count only moderate-to-vigorous physical activity (MVPA) in bouts lasting at least 10 min. However, it remains unclear men are truly more physically active provided that all-intensity PA are evaluated. This population based cross-sectional study aimed to examine gender differences in patterns of objectively-assessed PA in older adults.

Methods: One thousand two hundred ten community-dwelling Japanese older adults who were originally randomly selected from residential registry of three municipalities were asked to respond a questionnaire and wear an accelerometer (HJA-350IT, Omron Healthcare). The prevalence of achieving current PA guidelines, $\geq 150 \mathrm{~min} /$ week MVPA in bouts lasting at least $10 \mathrm{~min}$, was calculated. Gender differences in volume of each-intensity activity (METs-hour) were assessed by analysis of covariance after adjustment for age and wear time.

Results: Data from 450 (255 men, mean 74 years) participants who had valid accelerometer data were analyzed. Women were less likely to meet the guidelines (men: 31.0, women: 21.5\%; $p<0.05$ ). However, women accumulated more light-intensity PA (LPA) and short-bout (1-9 min) MVPA, and thus established higher total volume of PA (men: 22.0 METs-hour/day, women: 23.9 METs-hour/day) ( $p<0.05)$.

Conclusions: Older women were less active when evaluated against current PA guidelines, but more active by total PA. Considering accumulated evidence on health benefits of LPA and short-bout MVPA, our findings highlight the potential for the limitation of assessing PA using current PA guidelines.
\end{abstract}

Keywords: Physical activity, Sedentary, Recommendation, Guideline, Accelerometry, Elderly, Epidemiology

\section{Background}

It has been estimated that men are more physically active than women in almost every country for most of the age groups when evaluated based on current physical activity (PA) guidelines [1-3]. Guidelines recommend that older adults engage in at least $150 \mathrm{~min}$ of moderate-tovigorous physical activity (MVPA) per week in bouts

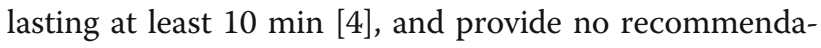
tions how the other time should be spent. Considering the accumulated evidence on health benefits of lower intensity [5-7] and fractionalized MVPA [6, 8], apart from

\footnotetext{
* Correspondence: inoue@tokyo-med.ac.jp

${ }^{1}$ Department of Preventive Medicine and Public Health, Tokyo Medical

University, 6-1-1 Shinjuku, Shinjuku-ku, Tokyo 160-8402, Japan

Full list of author information is available at the end of the article
}

long-bout ( $\geq 10 \mathrm{~min}$ ) MVPA, it may be necessary to consider other activities when determining PA levels, such as sedentary behavior (SB), light-intensity physical activity (LPA) and short-bout ( $<10 \mathrm{~min})$ MVPA. Higher LPA level is beneficially associated with mortality risk [7, 911 ] and sitting for a prolonged time negatively effects metabolic and cardiovascular health independent of MVPA [12-14].

The ubiquitous presence of lower intensity and sporadic PA could make them partly difficult to recall in questionnaire surveys [15], though such behaviors may be of particular importance, especially for older adults for whom it is hard to accumulate long-bout MVPA [5, $6,16]$. Even though self-report based assessment of PA, which has some limitations [17], has been widely used in 
a research setting [1], using a motion sensor worn on the body, or accelerometer, to objectively measure PA can now give a better and more accurate understanding of personal daily activity patterns [18].

To the best of our knowledge, it remains unclear men are truly more physically active provided that all-intensity PA are evaluated. Therefore, the aim of this study was to examine gender differences in patterns of objectivelyassessed PA in older adults. Our hypothesis is that women are less active according to the current PA guidelines, but more active when assessed based on total volume of PA owing to light and sporadic PA derived from life-style related PA (e.g. housework).

\section{Methods}

\section{Study design}

This cross-sectional epidemiological study was conducted from February through June in 2015. The study sample was 1,210 Japanese older adults aged 70-79 years who took part in a community-based survey carried out in 2010 [19]. Age, gender, and residential area had been already obtained from the resident registries of municipalities in 2010. Participants were originally randomly selected from three areas in Japan: Bunkyo city and Fuchu city in Tokyo, and Oyama City in Shizuoka prefecture. The details of the sampling process for the 2010 survey and the locations, areas, population sizes, and population densities of each area are described in the previous study [19].

\section{Questionnaire data}

Educational attainment (years of education), working status (working with income/ not working), living arrangement (with others/alone), driving status (driving/ not driving), and self-rated health were evaluated by self-report questionnaire conducted in 2015. Body mass index (BMI) $\left(\mathrm{kg} / \mathrm{m}^{2}\right)$ was calculated from self-reported height and weight. Self-rated health was assessed with one item from SF-8 (Japanese version) that asked participants to rate their health. Participants chose the answer that most accurately describes from a 6-point scale: excellent, very good, good, fair, poor and very poor, to the question; "Overall, how would you rate your health during the past 4 weeks?" [20].

\section{Accelerometry}

SB and PA were assessed using a tri-axial accelerometer, the Active style Pro HJA-350IT (Omron Healthcare, Japan), with a 60-s epoch length. Metabolic equivalents (METs) determined by the Active style Pro have been shown to be strongly correlated with METs measured by indirect calorimetry [21], and accurately estimate energy expenditure in free-living conditions [22]. In addition, validity of the accelerometry used in this study has been confirmed in older people [23]. Active style Pro HJA$350 \mathrm{IT}$ does not assess posture and SB was determined by acceleration. METs-based cutoff was used to define each intensity of activity: $\leq 1.5$ METs for SB, 1.6-2.9 METs for LPA, 3.0-5.9 METs for moderate-intensity PA (MPA), $\geq 6$ METs for vigorous-intensity PA (VPA), and $\geq 3$ METs for MVPA [12, 24, 25].

Participants were asked to wear the accelerometer on their waist for seven consecutive days while awake, only taking it off for water-based activities (e.g., swimming and shower). We adapted the records as follows: records taken when wearing the accelerometer for at least $10 \mathrm{~h}$ per day were considered validated records [26], and defined as "non-wear" if no acceleration signal was observed for more than 60 consecutive minutes. Participants with data from at least four days regardless of week/weekend were included in the analysis in this study. If participants had accelerometer data with more than seven days, that was also included accordingly.

\section{Statistical analysis}

Chi-squared test was conducted to compare participant characteristics between those who agreed to wear an accelerometer and those who did not. Gender differences between categorical variables were calculated using the chi-square test. BI-LINK PROFESSIONAL EDITION Ver1.0 (Omron Healthcare, Japan) was used to analyze accelerometer data. Descriptive analyses of the duration ( $\mathrm{min} /$ day) and volume (metabolic equivalents $\mathrm{x}$ hours) (METs-hour) in SB, LPA, and MVPA were conducted, stratified by gender. Total MVPA was further divided into two types according to the length of MVPA-bout: short-bout MVPA (1-9 $\mathrm{min}$ ) and long-bout MVPA ( $\geq 10 \mathrm{~min}$ ). Long-bout MVPA was defined as 10 or more consecutive minutes above moderate intensity threshold, on the condition that one or two minutes of interruption was allowed $[8,26]$. The total minutes per week of longbout MVPA was also calculated and prevalence of achieving more than $150 \mathrm{~min} /$ week (i.e., meeting the current PA guidelines) was obtained.

LPA time was normally distributed. As daily minutes of SB and MVPA were not normally distributed (Shapiro-Wilk test: $p<0.05)$, median and quartiles $(25 \%$, $75 \%$ ) as well as mean and standard deviation (SD) were calculated. To eliminate the effect of different wear time between genders, we also described the percentage of wear time in each activity [i.e., PA time (min/day) /total wear time $(\mathrm{min} /$ day)*100]. Gender differences in each activity time were examined using t-test or MannWhitney U test, as appropriate. Total volume of each activity (METs-hour) per day was assessed by analysis of covariance (ANCOVA) after adjustment for age and wear time. Models were re-run using additional adjustment for sociodemographic factors (residential area, 
living arrangement, working status, educational attainment, and driving status). The significance level was set at $p<0.05$. All statistical analyses were conducted using IBM SPSS Statistics version 21 (SPSS Inc., Tokyo, Japan).

\section{Results}

\section{Participant enrolment and characteristics}

Of the 1,210 surveyed, 988 older adults completed the questionnaire (response rate: $81.7 \%$ ), and 478 of those agreed to wearing the accelerometer. However, 28 were excluded for; not meeting wearing time criteria (i.e., wearing at least four days of $\geq 10 \mathrm{~h} /$ day) $(n=7)$, refusal to wear or unreturned accelerometer $(n=15)$, and system error $(n=6)$. Thus, a total number of 450 older adults (men: 255, women: 195) was included in this study. When comparisons of participant characteristics were made between those who agreed to wear an accelerometer and those who did not, significant differences were found in gender (the percentage of agreement; men: 55.6\%, women: $47.7 \%)$ and educational attainment ( $<13$ years: $48.6 \%, \geq 13$ years: $57.3 \%)$. In analyses stratified by gender, significant differences between those who agreed to wear an accelerometer and those who did not were observed in educational attainment $(<13$ years: $50.2 \%, \geq 13$ years: $62.2 \%$ ) and self-rated health (excellent: $65.0 \%$, very good: $63.0 \%$, good: $56.1 \%$, fair: $54.7 \%$, poor: $38.9 \%$, and very poor: $0.0 \%$ ) in men while no differences between them were observed in women.

The mean age was $74.3 \pm 2.9$ years in men and $74.4 \pm 2.8$ years in women and proportion of participants did not significantly vary by residential area (Table $1)$. Most of the study population was living with others, $<25.0$ BMI. There were statistically significant gender differences in educational attainment, working status, self-rated health, driving status $(p<0.05)$.

\section{Patterns of physical activity}

Mean wear time was $854.9 \mathrm{~min} /$ day in men and $898.6 \mathrm{~min} /$ day in women. Older adults spent $94.9 \%$ of wear time on SB and LPA, whereas they engaged only $5.1 \%$ for MVPA (Table 2). MPA accounted for more than 99\% of MVPA in both genders. More LPA (men: $263.1 \mathrm{~min} /$ day, women: $365.3 \mathrm{~min} /$ day) and less SB (men: $548.3 \mathrm{~min} /$ day, women: $487.0 \mathrm{~min} /$ day) time was observed among women, while total MVPA time (men: $43.6 \mathrm{~min} /$ day, women: $46.3 \mathrm{~min} /$ day) did not differ by gender. Adjusting for wear time did not alter the results. When reviewing the breakdown of MVPA, more shortbout MVPA (men: $25.7 \mathrm{~min} /$ day, women: $33.6 \mathrm{~min} /$ day) was observed among women. In contrast, men engaged in more long-bout MVPA (men: $17.9 \mathrm{~min} /$ day, women: $12.7 \mathrm{~min} /$ day), thus the proportion of older adults who met PA guidelines (i.e. $\geq 150 \mathrm{~min} /$ week) was statistically higher in men (men: 31.0\%, women: 21.5\%) $(p<0.05)$
(Fig. 1). On the other hand, total volume of PA among women was greater compared with men [men: 22.0 (95\% confidential interval: 21.7, 22.3) METs-hour, women: $23.9(23.5,24.3)$ METs-hour] $(p<0.05)$ owing to considerably higher LPA [men: 9.4 (9.0, 9.8) METs-hour, women: 12.7 (12.3, 13.2) METs-hour], and higher shortbout MVPA [men: $1.5(1.4,1.6)$ METs-hour, women: 1.9 (1.7, 2.0) METs-hour] (Fig. 1). When ANCOVA was conducted with additional adjustment for sociodemographic factors, results were unchanged. Women significantly accumulated more LPA [men: 9.3 (1.3, 1.6) METs-hour, women: 12.9 (12.5, 13.4) METs-hour] and short bout MVPA [men: 1.5 (21.7, 22.3) METs-hour, women: 1.9 (1.7, 2.1) METs-hour], while men accumulated more SB [men: $10.0(9.8,10.2)$ METs-hour, women: 8.5 (8.3, 8.8) METs-hour] and long bout MVPA [men: 1.2 $(1.0,1.4)$ METs-hour, women: $0.7(0.5,0.9)$ METs-hour]. Accordingly, women established higher total volume of PA than men [men: 9.4 (9.0, 9.8) METs-hour, women: 12.7 (12.3, 13.2) METs-hour].

\section{Discussion}

Our findings provide a detailed analysis of PA patterns in Japanese older men and women. In summary, older women were less physically active when evaluated against current PA guidelines, but more active by total volume of PA. Considerably less time spent in SB, longer LPA and short-bout MVPA time in women were observed, which can likely be explained by lifestyle differences; Japanese women have traditionally been more responsible for most of the housework than men.

Several cohort studies have confirmed associations between longer sedentary time and higher all-cause mortality in older adults [27-29]. Epidemiological evidence is accumulating that indicates greater time spent in objectively-assessed LPA is beneficially associated with all-cause mortality [7, 9-11], cardiometabolic health [5, 30-33], mental health [31, 34, 35], and well-being [36]. As Loprinzi et al.'s study showed, for example, participants had a $16 \%$ reduced hazard of all-cause mortality [hazard ratio: $0.84 ; 95 \%$ CI: $0.78,0.91$ ] for every 60 -min increase in LPA independent of objectively-measured MVPA [9]. In our sample, there was a big difference of LPA time between genders $(263.1 \mathrm{~min} /$ day in men and $365.3 \mathrm{~min} /$ day in women). Approximately $100 \mathrm{~min}$ of LPA difference between men and women, therefore, is considered to have a meaningful impact on health outcomes. Moreover, several studies using accelerometers suggest short-bout MVPA improves metabolic health [8, 37-39]. Glazer et al.'s study [8], for example, confirmed a positive associations of short-bout MVPA with favorable cardiovascular disease risk including BMI, triglycerides, and Framingham risk score. Another study [37] indicates that accumulating MVPA in short-bout, 
Table 1 Participant characteristics

\begin{tabular}{|c|c|c|c|}
\hline & $\begin{array}{l}\text { Men } \\
(n=255)\end{array}$ & $\begin{array}{l}\text { Women } \\
(n=195)\end{array}$ & \\
\hline & $n(\%)$ & $n(\%)$ & $P$-value \\
\hline$\overline{\text { Age }}$ & & & 0.924 \\
\hline 70-74 years & $132(51.8 \%)$ & $102(52.3 \%)$ & \\
\hline $75-79$ years & $123(48.2 \%)$ & $93(47.7 \%)$ & \\
\hline Residential area & & & 0.084 \\
\hline Bunkyo & 78 (30.6\%) & $64(32.8 \%)$ & \\
\hline Fuchu & 91 (35.7\%) & $51(26.2 \%)$ & \\
\hline Oyama & $86(33.7 \%)$ & $80(41.0 \%)$ & \\
\hline Educational attainment & & & $<0.001$ \\
\hline$<13$ years (Up to high school) & $118(46.3 \%)$ & $132(68.0 \%)$ & \\
\hline $\begin{array}{l}\geq 13 \text { years (College degree or } \\
\text { more) }\end{array}$ & $137(53.7 \%)$ & $62(32.0 \%)$ & \\
\hline Living arrangement & & & 0.076 \\
\hline with others & $225(88.6 \%)$ & $161(82.6 \%)$ & \\
\hline alone & $29(11.4 \%)$ & $34(17.4 \%)$ & \\
\hline Working with income & & & $<0.001$ \\
\hline working & $94(36.9 \%)$ & $37(19.2 \%)$ & \\
\hline not working & $161(63.1 \%)$ & $156(80.8 \%)$ & \\
\hline Body mass index (BMI) & & & 0.084 \\
\hline$<25.0 \mathrm{~kg} / \mathrm{m}^{2}$ & 199 (78.0\%) & $164(85.0 \%)$ & \\
\hline$\geq 25.0 \mathrm{~kg} / \mathrm{m}^{2}$ & $56(22.0 \%)$ & $29(15.0 \%)$ & \\
\hline Self-rated health & & & 0.031 \\
\hline excellent & $12(4.7 \%)$ & $5(2.6 \%)$ & \\
\hline very good & $58(22.9 \%)$ & $41(21.1 \%)$ & \\
\hline good & $147(58.1 \%)$ & $100(51.5 \%)$ & \\
\hline fair & $32(12.6 \%)$ & $36(18.6 \%)$ & \\
\hline poor & $4(1.6 \%)$ & $9(4.6 \%)$ & \\
\hline very poor & $0(0.0 \%)$ & $3(1.5 \%)$ & \\
\hline Driving status & & & $<0.001$ \\
\hline driving & $160(62.7 \%)$ & 49 (25.3\%) & \\
\hline not driving & 95 (37.3\%) & 145 (74.7\%) & \\
\hline \multicolumn{3}{|l|}{$\begin{array}{l}\text { Moderate to vigorous physical } \\
\text { activity }\end{array}$} & 0.032 \\
\hline $\begin{array}{l}<150 \mathrm{~min} / \text { week } \\
\text { (not meeting guideline) }\end{array}$ & $176(69.0 \%)$ & 153 (78.5\%) & \\
\hline $\begin{array}{l}\geq 150 \mathrm{~min} / \text { week (meeting } \\
\text { guideline) }\end{array}$ & $79(31.0 \%)$ & $42(21.5 \%)$ & \\
\hline
\end{tabular}

$P$-value was calculated by chi-square test. Bold indicates statistical significance $(p<0.05)$

compared with long-bout, might be just as beneficial in improvements of biologic health outcomes. In the present study, relative to men, women spent less time long-bout MVPA, but more time in short-bout MVPA (approximately $8 \mathrm{~min}$ ). Presumably, women benefit more from short-bout MVPA than men. These activities, though not recommended by guidelines, may confer health benefits besides those well-established for MVPA [40].

With regard to total volume of PA, Manini et al. [41] found that objectively-measured (using doubly labeled water) free-living activity energy expenditure (EE) was strongly associated with reduced risk of mortality in healthy older adults, and they indicates expending EE through any activity may influence survival. Another recent study by Salonen et al. [42] reported that objectively-determined total PA volume was beneficially associated with various components of metabolic syndrome including waist circumstance, blood pressure, cholesterol, triglycerides, and fasting glucose.

For those described above, PA level and patterns specific to women may partly contribute to Japanese women's longevity compared with men. PA level and patterns have not yet been addressed to explain why women live longer than men. One reason is that it has been estimated that men are more physically active than women in almost every country for most of the age groups when evaluated based on the current PA guidelines [1-3], where short-bout MVPA and LPA are overlooked [4].

\section{Implications of our findings}

In this study, men who tend to achieve $150 \mathrm{~min} /$ week MVPA do not necessarily accumulate a greater level of LPA than women. In contrast, not meeting $150 \mathrm{~min} /$ week MVPA does not always correspond to a lower level of LPA as shown in women. Accordingly, looking at only MVPA become blind to the substantial benefits of PA including LPA. The results of this study suggest that evaluation criteria on PA level and public health message should be refined to include LPA in order to take PA patterns into account. In practice, we have to be careful when identifying population groups in need of interventions since there may be the discrepancy between meeting PA guidelines and total volume of PA. Older men who meet current PA guidelines but spend most of their time SB are also target of future interventions to increase LPA. For older women who are active in LPA, future research is needed to assess the health benefits by additional MVPA.

\section{Strengths and limitations}

Our study is the novel investigation of gender differences in PA patterns including SB, LPA, and different durations of MVPA in one study which goes beyond previous studies that just examined total MVPA and longbout MVPA [26, 43] or did not include all-intensity PA [44]. PA and SB were objectively measured by a tri-axial accelerometer, which has a validated algorithm [21, 45]. It is reported that Active style Pro HJA-350IT can be an accurate measurement for $\mathrm{EE}$ in free-living condition 
Table 2 Time spent in objectively- measured physical activity by intensity in Japanese older men and women

\begin{tabular}{|c|c|c|c|c|c|c|c|c|c|}
\hline & \multicolumn{4}{|l|}{ Men $(n=255)$} & \multicolumn{5}{|c|}{ Women $(n=195)$} \\
\hline & mean $\pm S D$ & median & $(25 \%, 75 \%)$ & $\%$ wear time & mean \pm SD & median & $(25 \%, 75 \%)$ & $\%$ wear time & $P$-value \\
\hline$\overline{S B}$ & $548.3 \pm 118.7$ & 551.1 & $(481.2,619.6)$ & 64.0 & $487.0 \pm 111.6$ & 481.9 & $(418.1,543.6)$ & 54.2 & $<0.001^{\mathrm{a}}$ \\
\hline LPA & $263.1 \pm 87.4$ & 260.6 & $(198.9,319.8)$ & 30.9 & $365.3 \pm 90.2$ & 359.3 & $(304.2,421.0)$ & 40.7 & $<0.001^{b}$ \\
\hline \multicolumn{10}{|l|}{ MVPA } \\
\hline Total MVPA & $43.6 \pm 30.1$ & 39.3 & $(20.4,60.6)$ & 5.1 & $46.3 \pm 32.8$ & 38.8 & $(21.3,65.6)$ & 5.1 & $0.526^{a}$ \\
\hline Short-bout MVPA & $25.7 \pm 17.0$ & 22.4 & $(13.0,34.9)$ & 3.0 & $33.6 \pm 23.2$ & 28.3 & $(16.5,43.7)$ & 3.7 & $<0.001^{\mathrm{a}}$ \\
\hline Long-bout MVPA & $17.9 \pm 21.2$ & 9.6 & $(2.5,25.9)$ & 2.1 & $12.7 \pm 15.9$ & 6.3 & $(1.1,19.6)$ & 1.4 & $0.012^{\mathrm{a}}$ \\
\hline
\end{tabular}

$P$-value was calculated by Mann-Whitney $\mathrm{U}$ test ${ }^{\mathrm{a}}$ or $\mathrm{t}$ test $\mathrm{t}^{\mathrm{b}}$. Bold indicates statistical significance $(p<0.05)$.

Abbreviations: SB sedentary behavior, LPA light-intensity physical activity, MVPA moderate-to-vigorous physical activity

Short-bout: lasting 1-9 min, long-bout: lasting $\geq 10 \mathrm{~min}$

[22], although a previous study indicates that PA intensities (i.e., METs) during walking can be somewhat underestimated in older adults [23]. Using tri-axial accelerometers can provide accurate estimates [46-48], and validated the estimated EE in lower intensity PA [46, 49]. In addition, our sample is community-dwelling older adults from different area rather than "at risk" clinical groups, so findings should be generalizable to wider older adult populations. Some limitations of this study need to be considered when interpreting results. First, although accelerometers provide objective measures, they cannot accurately detect postural information (i.e., standing vs. sitting) and capture some types of PA (e.g. bicycling, water-based activities), thus these activities might be uncounted or under/overestimated [18]. However, regarding the results of questionnaire and a simple personal log by self-reported simultaneously carried out in this study, these activities accounted for only a very small proportion of total PA performed by older adults during the adopted days to the analyses. Second, we

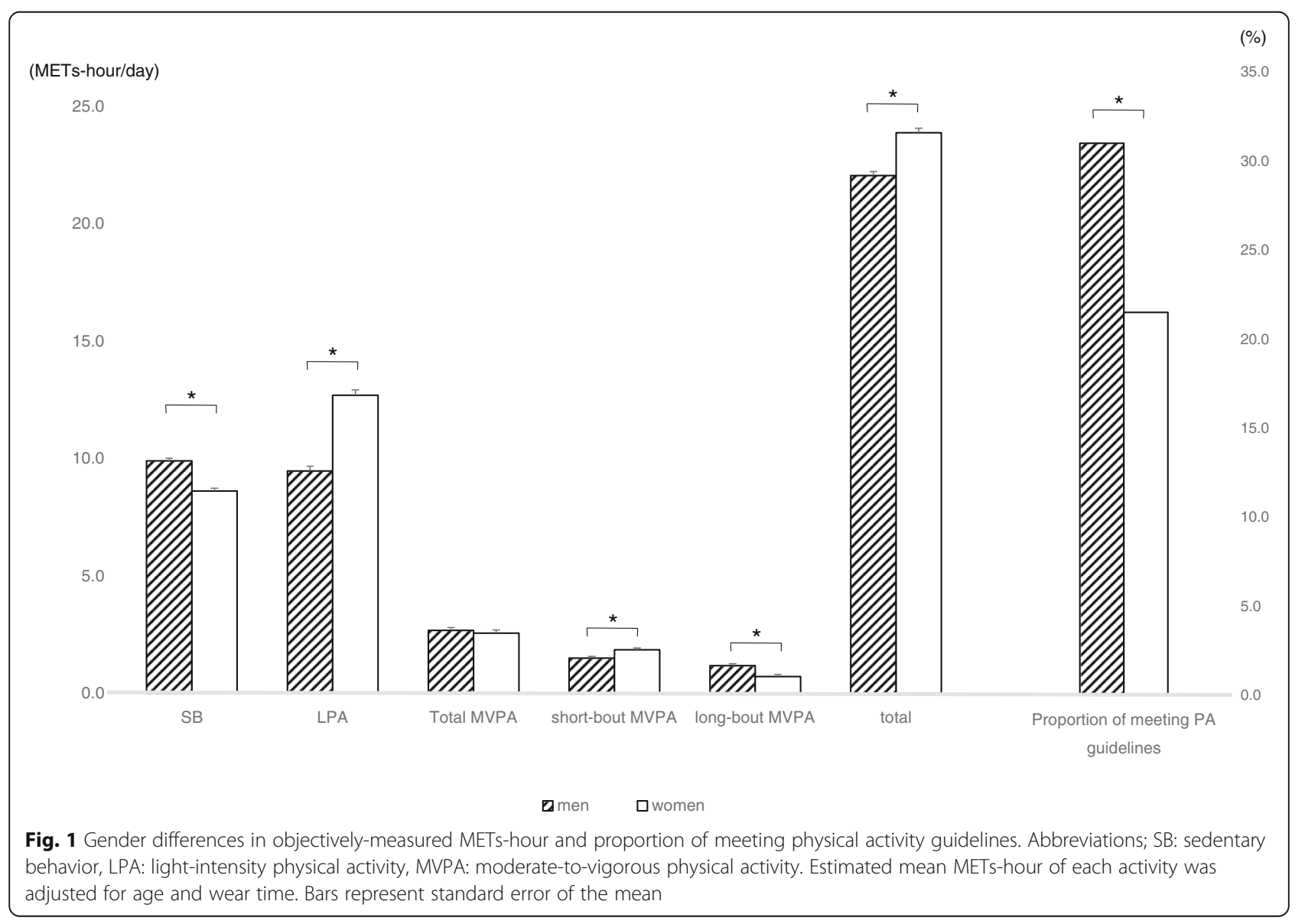


need to consider selection bias. In our sample, response rates were slightly different between men and women. There is a possibility that PA patterns may differ between those who agreed to wear an accelerometer and those who did not. Finally, the age range of our sample was relatively narrow. Our findings of this study might not be generalized to the other elderly population (e.g., $\geq 80$ years). Further research including more wide range of older people is needed.

\section{Conclusions}

Patterns of objectively-assessed PA were greatly differed by gender in community-dwelling older adults in Japan. Older women were less physically active than older men when evaluated against current PA guidelines, but more active by total volume of PA including LPA and shortbout MVPA. Considering accumulated evidence on health benefits of light and sporadic PA, our findings highlight the potential for the limitation of assessing PA using current guidelines.

\section{Abbreviations}

BMI: Body mass index; EE: Energy expenditure; LPA: Light-intensity physical activity; METs: Metabolic equivalents; MVPA: Moderate-to-vigorous physical activity; PA: Physical activity; SB: Sedentary behavior

\section{Acknowledgements}

We express our sincere thanks to all the participants who responded the questionnaire and wore accelerometer for this study. We are most grateful to the funding bodies which supported our research.

\section{Funding}

This study was supported by a Grant-in-Aid for Scientific Research (20500604 and 16H03249) from the Japan Ministry of Education, Culture, Sports, Science and Technology, and the Uehara Memorial Foundation.

\section{Availability of data and material}

The datasets analyzed during the current study are not publicly available due to access restrictions imposed by the Tokyo Medical University Ethics Committee but are available from the corresponding author on reasonable request.

\section{Authors' contributions}

SI developed the study design and all authors collected the data. SA conducted statistical analyses and prepared the draft version of the manuscript. NF, HK, T, KO and SI participated in the interpretation of the data, revised the draft versions of the manuscript and provided critical comments during the process. All authors read and approved the final version of the manuscript.

\section{Competing interests}

The authors declare that they have no competing interests.

\section{Consent for publication}

Not applicable.

\section{Ethical approval and consent to participate}

Ethical approval was obtained from the Tokyo Medical University Ethics Committee prior to the survey (No. 2898). Written informed consent was obtained from all participants.

\section{Publisher's Note}

Springer Nature remains neutral with regard to jurisdictional claims in published maps and institutional affiliations.

\section{Author details}

${ }^{1}$ Department of Preventive Medicine and Public Health, Tokyo Medical University, 6-1-1 Shinjuku, Shinjuku-ku, Tokyo 160-8402, Japan. ${ }^{2}$ Faculty of Sport Sciences, Waseda University, 2-579-15 Mikajima, Tokorozawa, Saitama 359-1192, Japan.

Received: 1 February 2017 Accepted: 22 April 2017

Published online: 02 May 2017

\section{References}

1. Hallal PC, Andersen LB, Bull FC, Guthold R, Haskell W, Ekelund U. Global physical activity levels: surveillance progress, pitfalls, and prospects. Lancet. 2012;380:247-57.

2. Sallis JF, Bull F, Guthold R, Heath GW, Inoue S, Kelly P, Oyeyemi AL, Perez LG, Richards J, Hallal PC. Progress in physical activity over the Olympic quadrennium. Lancet. 2016;388:1325.

3. Sun F, Norman IJ, While AE. Physical activity in older people: a systematic review. BMC Public Health. 2013;13:449.

4. World Health Organization (WHO): Global recommendations on physical activity for health. 2010. http://apps.who.int/iris/bitstream/10665/44399/1/ 9789241599979_eng.pdf Accessed 11 May 2016.

5. Loprinzi PD, Lee H, Cardinal BJ. Evidence to support including lifestyle lightintensity recommendations in physical activity guidelines for older adults. Am J Health Promot. 2015;29:277-84.

6. Jefferis BJ, Parsons TJ, Sartini C, Ash S, Lennon LT, Wannamethee SG, Lee IM, Whincup PH. Does duration of physical activity bouts matter for adiposity and metabolic syndrome? A cross-sectional study of older British men. Int J Behav Nutr Phys Act. 2016;13:36.

7. Beddhu S, Wei G, Marcus RL, Chonchol M, Greene T. Light-intensity physical activities and mortality in the United States general population and CKD subpopulation. Clin J Am Soc Nephrol. 2015;10:1145-53.

8. Glazer NL, Lyass A, Esliger DW, Blease SJ, Freedson PS, Massaro JM, Murabito JM, Vasan RS. Sustained and shorter bouts of physical activity are related to cardiovascular health. Med Sci Sports Exerc. 2013;45:109-15.

9. Loprinzi PD. Light-intensity physical activity and all-cause mortality. Am J Health Promot. 2016;

10. Ensrud KE, Blackwell TL, Cauley JA, Dam TT, Cawthon PM, Schousboe JT, Barrett-Connor E, Stone KL, Bauer DC, Shikany JM, Mackey DC. Objective measures of activity level and mortality in older men. J Am Geriatr Soc. 2014;62:2079-87.

11. Fishman El, Steeves JA, Zipunnikov V, Koster A, Berrigan D, Harris TA, Murphy R. Association between objectively measured physical activity and mortality in NHANES. Med Sci Sports Exerc. 2016;48:1303-11.

12. Owen N, Healy GN, Matthews CE, Dunstan DW. Too much sitting: the population health science of sedentary behavior. Exerc Sport Sci Rev. 2010; 38:105-13.

13. Young DR, Hivert MF, Alhassan S, Camhi SM, Ferguson JF, Katzmarzyk PT, Lewis CE, Owen N, Perry CK, Siddique J, Yong CM. Sedentary behavior and cardiovascular morbidity and mortality: a science advisory from the American Heart Association. Circulation. 2016;134:e262-79.

14. de Rezende LF, Rey-Lopez JP, Matsudo VK, do Carmo Luiz O. Sedentary behavior and health outcomes among older adults: a systematic review. BMC Public Health. 2014;14:333.

15. Washburn RA. Assessment of physical activity in older adults. Res Q Exerc Sport. 2000;71:S79-88.

16. Sparling PB, Howard BJ, Dunstan DW, Owen N. Recommendations for physical activity in older adults. BMJ. 2015;350:h100.

17. Shephard RJ. Limits to the measurement of habitual physical activity by questionnaires. Br J Sports Med. 2003;37:197-206. discussion 206

18. Shephard RJ, Tudor-Locke C. The objective monitoring of physical activity: contributions of Accelerometry to epidemiology, exercise science and rehabilitation: Springer International Publishing; 2016. http://www.springer. com/us/book/9783319295756.

19. Inoue S, Ohya Y, Odagiri Y, Takamiya T, Kamada M, Okada S, Oka K, Kitabatake Y, Nakaya T, Sallis JF, Shimomitsu T. Perceived neighborhood environment and walking for specific purposes among elderly Japanese. J Epidemiol. 2011;21:481-90.

20. Tokuda Y, Okubo T, Ohde S, Jacobs J, Takahashi O, Omata F, Yanai H, Hinohara S, Fukui T. Assessing items on the SF-8 Japanese version for health-related quality of life: a psychometric analysis based on the nominal categories model of item response theory. Value Health. 2009;12:568-73. 
21. Oshima Y, Kawaguchi K, Tanaka S, Ohkawara K, Hikihara Y, Ishikawa-Takata K, Tabata I. Classifying household and locomotive activities using a triaxial accelerometer. Gait Posture. 2010;31:370-4.

22. Murakami H, Kawakami R, Nakae S, Nakata Y, Ishikawa-Takata K, Tanaka S, Miyachi M. Accuracy of wearable devices for estimating Total energy expenditure: comparison with metabolic chamber and doubly Labeled water method. JAMA Intern Med. 2016;176:702-3.

23. Park J, Ishikawa-Takata K, Tanaka S, Bessyo K, Tanaka S, Kimura T. Accuracy of estimating step counts and intensity using accelerometers in older people with or without assistive devices. J Aging Phys Act. 2017;25:41-50.

24. Ainsworth BE, Haskell WL, Whitt MC, Irwin ML, Swartz AM, Strath SJ, O'Brien WL, Bassett DR Jr, Schmitz KH, Emplaincourt PO, et al. Compendium of physical activities: an update of activity codes and MET intensities. Med Sci Sports Exerc. 2000;32:S498-504

25. Sedentary Behaviour Research N. Letter to the editor: standardized use of the terms "sedentary" and "sedentary behaviours". Appl Physiol Nutr Metab. 2012;37:540-2.

26. Troiano RP, Berrigan D, Dodd KW, Masse LC, Tilert T, McDowell M. Physical activity in the United States measured by accelerometer. Med Sci Sports Exerc. 2008;40:181-8

27. Martinez-Gomez D, Guallar-Castillon P, Leon-Munoz LM, Lopez-Garcia E, Rodriguez-Artalejo F. Combined impact of traditional and non-traditional health behaviors on mortality: a national prospective cohort study in Spanish older adults. BMC Med. 2013;11:47.

28. Pavey TG, Peeters GG, Brown WJ. Sitting-time and 9-year all-cause mortality in older women. Br J Sports Med. 2015;49:95-9.

29. Leon-Munoz LM, Martinez-Gomez D, Balboa-Castillo T, Lopez-Garcia E, GuallarCastillon P, Rodriguez-Artalejo F. Continued sedentariness, change in sitting time, and mortality in older adults. Med Sci Sports Exerc. 2013;45:1501-7.

30. Healy GN, Dunstan DW, Salmon J, Cerin E, Shaw JE, Zimmet PZ, Owen N. Objectively measured light-intensity physical activity is independently associated with 2-h plasma glucose. Diabetes Care. 2007;30:1384-9.

31. Loprinzi PD, Lee $H$, Cardinal BJ. Dose response association between physical activity and biological, demographic, and perceptions of health variables. Obes Facts. 2013;6:380-92.

32. Lynch BM, Friedenreich CM, Winkler EA, Healy GN, Vallance JK, Eakin EG, Owen N. Associations of objectively assessed physical activity and sedentary time with biomarkers of breast cancer risk in postmenopausal women: findings from NHANES (2003-2006). Breast Cancer Res Treat. 2011;130:183-94.

33. Howard B, Winkler EA, Sethi P, Carson V, Ridgers ND, Salmon JO, Healy GN, Owen N, Dunstan DW. Associations of low- and high-intensity light activity with Cardiometabolic biomarkers. Med Sci Sports Exerc. 2015:47:2093-101.

34. Loprinzi PD. Objectively measured light and moderate-to-vigorous physical activity is associated with lower depression levels among older US adults. Aging Ment Health. 2013;17:801-5.

35. Buman MP, Hekler EB, Haskell WL, Pruitt L, Conway TL, Cain KL, Sallis JF, Saelens $B E$, Frank LD, King AC. Objective light-intensity physical activity associations with rated health in older adults. Am J Epidemiol. 2010;172:1155-65.

36. Ku PW, Fox KR, Liao Y, Sun WJ, Chen LJ. Prospective associations of objectively assessed physical activity at different intensities with subjective well-being in older adults. Qual Life Res. 2016;25:2909-19.

37. Loprinzi PD, Cardinal BJ. Association between biologic outcomes and objectively measured physical activity accumulated in $>/=10$-minute bouts and <10-minute bouts. Am J Health Promot. 2013;27:143-51.

38. Luke A, Dugas LR, Durazo-Arvizu RA, Cao G, Cooper RS. Assessing physical activity and its relationship to cardiovascular risk factors: NHANES 20032006. BMC Public Health. 2011;11:387.

39. Gay JL, Buchner DM, Schmidt MD. Dose-response association of physical activity with HbA1c: intensity and bout length. Prev Med. 2016;86:58-63.

40. Nelson ME, Rejeski WJ, Blair SN, Duncan PW, Judge JO, King AC, Macera CA, Castaneda-Sceppa C. Physical activity and public health in older adults: recommendation from the American College of Sports Medicine and the American Heart Association. Circulation. 2007;116:1094-105.

41. Manini TM, Everhart JE, Patel KV, Schoeller DA, Colbert LH, Visser M, Tylavsky F, Bauer DC, Goodpaster BH, Harris TB. Daily activity energy expenditure and mortality among older adults. JAMA. 2006;296:171-9.

42. Salonen MK, Wasenius N, Kajantie E, Lano A, Lahti J, Heinonen K, Raikkonen K, Eriksson JG. Physical activity, body composition and metabolic syndrome in young adults. PLoS One. 2015;10:e0126737.

43. Salvo D, Torres C, Villa U, Rivera JA, Sarmiento OL, Reis RS, Pratt M Accelerometer-based physical activity levels among Mexican adults and their relation with sociodemographic characteristics and BMI: a crosssectional study. Int J Behav Nutr Phys Act. 2015;12:79.

44. Tanaka C, Fujiwara Y, Sakurai R, Fukaya T, Yasunaga M, Tanaka S. Locomotive and non-locomotive activities evaluated with a triaxial accelerometer in adults and elderly individuals. Aging Clin Exp Res. 2013;25:637-43.

45. Ohkawara K, Oshima Y, Hikihara Y, Ishikawa-Takata K, Tabata I, Tanaka S. Real-time estimation of daily physical activity intensity by a triaxial accelerometer and a gravity-removal classification algorithm. Br J Nutr. 2011; 105:1681-91.

46. Yamada Y, Yokoyama K, Noriyasu R, Osaki T, Adachi T, Itoi A, Naito Y, Morimoto T, Kimura M, Oda S. Light-intensity activities are important for estimating physical activity energy expenditure using uniaxial and triaxial accelerometers. Eur J Appl Physiol. 2009;105:141-52.

47. Hendelman D, Miller K, Baggett C, Debold E, Freedson P. Validity of accelerometry for the assessment of moderate intensity physical activity in the field. Med Sci Sports Exerc. 2000;32:S442-9.

48. Levine JA, Baukol PA, Westerterp KR. Validation of the Tracmor triaxial accelerometer system for walking. Med Sci Sports Exerc. 2001;33:1593-7.

49. Midorikawa T, Tanaka S, Kaneko K, Koizumi K, Ishikawa-Takata K, Futami J, Tabata I. Evaluation of low-intensity physical activity by triaxial accelerometry. Obesity (Silver Spring). 2007;15:3031-8.

\section{Submit your next manuscript to BioMed Central and we will help you at every step:}

- We accept pre-submission inquiries

- Our selector tool helps you to find the most relevant journal

- We provide round the clock customer support

- Convenient online submission

- Thorough peer review

- Inclusion in PubMed and all major indexing services

- Maximum visibility for your research

Submit your manuscript at www.biomedcentral.com/submit

) Biomed Central 